\title{
Impact of Bryophyte on Soil Nutrients in Wudalianchi World Geopark
}

\author{
Zheng Yanbing, Liu Dongying and Wu Qiong
}

Heihe College, Heilongjiang, China

Keywords: bryophyte; Wudalianchi; volcanic lava landform; mineral elements; coverage; life form

\begin{abstract}
In order to understand the main mineral nutrients content and characteristics of the volcanic lava landforms in Wudalianchi, and to explore the effects of bryophytes on the accumulation of soil nutrients, six volcanoes in different ages were selected, and the habitat distribution, coverage and soil nutrient content of the mosses were investigated. The results were as follows: (1) the species of moss under the old volcanic broad-leaved forest in the Western Jiao Debo mountain, the supine tiger mountain, the nagaruoan mountain and the Maobu Shan mountain were $<1 \%$, and the moss of the old volcanic stone pond were more abundant and the coverage was $10 \%$ to $15 \%$, mainly distributed in the spyophytes such as the Maojian purple calyx moss, the moss, and the sphagnum, seam moss and leaf fissidens etc. (2) the dominant species in the Xingan Larix forest of the old black mountain in the new period volcano is the dominant species of the sphagnum. The coverage is $50 \%$ $80 \%$. The common species include moss, Ye Xiaoyu, moss and Maojian. The sand and mosses are dominant species in the habitats of the old black hills. The coverage is up to $45 \%$. The associated species are vertical branches, mosses, mosses, and haired moss. (3) the mosses distributed on the fire mountain in the new volcano are mainly dry stone mosses, such as Maojian purple calyx moss, sphagnum, moss, and so on. The coverage is about $10 \%$. There are three petal moss, Maojian moss and juniper moss in the cliffs and sew.
\end{abstract}

\section{Introduction}

As the main factor of the environment, soil will inevitably affect the succession of plant community, and the vegetation characteristics also affect the formation and development of soil; the succession of plant community is the process of adapting to the change of the initial state of the environment. The community characteristics and soil characteristics of different succession stages are the results of the coordinated development of vegetation and soil.

\section{Overview of the Effects of Bryophytes on Soil}

A moss plants as in the process of succession of pioneer plants, the algae and lichens, the first to enter the volcano habitat. They are not only resistant to drought, but also can grow on bare rock surfaces, such as purple calyx moss, true mosses, and so on, with strong light, water evaporation and water seepage. They can secrete acid metabolites, gradually dissolve rock surface, accelerate the rock weathering speed, and play an extremely important role in the formation of thin layer soil on the rock surface.

The plants of the bryophyte are small, usually only a few millimeters to a centimeter long, and a few can reach dozens of centimeters. Although moss is small, it has a huge surface area and extremely strong adsorption capacity, and often grows in large area of old school plexiform community, forming a large amount of capillary space, so the large area of moss and Xue plants can effectively intercept precipitation, column storage and runoff. Bryophytes have water absorption and water holding capacity, and the water absorbency of the general species reaches several times the weight of moss itself, and the water absorption of peat Xue can reach more than ten times of its own weight, and some species of community can even reach several times of its own weight. Studies have shown that the saturated water absorption of bryophyte communities is generally $200-600 \mathrm{~g} / \mathrm{m} 2$, and some 
species can reach 2000 - 3000g/m2 or even more than $3000 \mathrm{~g} / \mathrm{m} 2$. For example, the saturated water absorption of the abandoned gold mine is $684.3 \mathrm{~g} / \mathrm{m} 2$, and the saturation water absorption of the abandoned mine is nearly $3600 \mathrm{~g} / \mathrm{tn} 2$. It can also help to maintain the soil and soil fertility by reducing the evaporation of water and the loss of mineral nutrients in the soil water and increasing the retention of nutrients. Bryophytes reduce wind speed by increasing the surface coarse sugar content, and accumulate essential elements such as sand and $\mathrm{K}, \mathrm{P}$ and $\mathrm{S}$ in the community. The amount of lichen soil is directly proportional to its dry weight and biomass. That is to say, the larger the bryophyte coverage and thicker the bryophyte layer is, the more soil will form. The leaves of the plant are usually composed of single layer cells or two layers of cells. There is no stratum corneum protection and lack of vascular system. Therefore, the water and mineral nutrients in the atmosphere are absorbed mainly through the surface of the plant body and enriched in the body.

\section{Investigation on the Coverage of Moss and Suzhou Plants in Volcanic Lava Landforms}

Bryophytes, as pioneer plants in succession, play a very important role in soil formation. The bryophyte community is beneficial to reduce wind and dust, produce the regulator and promote the improvement of soil surface stratification, and to improve the structure of soil, the accumulation of organic matter and nitrogen in the surface soil.

\subsection{Bryophyte coverage and analysis of old montenegrin}

The old black mountain (E 126 07.173', N48 42.819', 509m) erupted from 1720 to 1721. It was one of the youngest volcanoes in the study area, and most of its volcanic cone and most of its surrounding volcano were covered by a thicker volcano. The hillside of the old black mountain covers the Larix Larix community in Xingan, the five colored sandy beaches, the foot of the mountain, the mixed forest of poplar, the birch forest, the poplar dwarf forest or the perennial herbaceous plant community dominated by the Potentilla. The volcano habitat under the mountain of old Heishan is the dominant species of stone mosses and sands. The coverage is $45 \%$. The common species are: the moss, the moss, the moss and the mosyophytes of the juniper. The bryophyte species in the lower Larix forest on the hillside of the old Heishan mountain are single, with the dominant species of the sphagnum, but the species can form a large area of ground cover: under the shady slope, the coverage can reach more than $80 \%$. In addition to the sphagnum of the hillside Larix forest, there are some associated species, such as sphagnum sphagus, moss in the narrow leaf, moss of fine lobes, moss golden gray, moss of Chinese shrinks, petal ear leaf moss, Maojian purple vane moss, and so on. In the old black mountain, the dry land and the sufficient illumination were mainly located in the dry moss, such as moss, chuba and Xue Xue, and the coverage of moss plants was less than $1 \%$. The lava platform around old black mountain is mainly covered with lichen one moss community, of which the highest coverage of bryophytes is up to 70\%; the main distribution is the dry stone species such as the Suzhou, the moss of the tiger tail, the moss, the Maojian purple calyx and so on.

\subsection{Bryophyte coverage and analysis of volcano}

Fire Mountain (E 126 09.306', 48 44.241', elevation 391m) erupted in 1721. It is another new period volcano in the study area. Its volcanic cone and its surrounding are covered with a thick layer of volcanic debris and volcanic rock, which is not often arid because of its weak weathering of volcanic basaltic flame rock and poor water retention, and the large area of karst platform is still in the soil. In the original stage of breeding, there were some aeolian soils in the low-lying land and rock seams, so there was almost no other vegetation except the lichen and bryophyte, and the habitat was very unitary. The coverage of mosaichi plants is about $10 \%$, and the dry stone mosses, such as Maojian, purple calyx moss and sweet gray moss, are the dominant species. There are also three vertical clam moss, dense leaves, golden haired moss, haired moss and so on. These moss plants played an important role in the formation and accumulation of soil. 


\section{Comparative Analysis of Nutrient Contents of Same Soil Samples}

\subsection{Comparison of nutrient contents in different soil samples from Laoheishan.}

Except for Zn in the soil samples collected by the old black mountain road, the content of the remaining nutrients is almost all lower than the fine volcano fishing and the unscreened coarse Fire Mountain samples collected under the old black mountain Larch pine forest. This may be related to the habitats collected by the sample, because the slag is collected under the mixed forest of a Xingan Larch on the slopes of the hillside of the old black mountain. There is a thick layer of litter layer under the forest, which provides a large amount of organic matter for the ground surface, while the soil samples are taken from the roadside ground in the foot of the old Montenegro mountain, with the exception of a small amount of moss and lichens. Other vegetation covers. The content of other nutrient elements in volcanic deposits is higher than that in roadside soils, indicating that the samples still retain their characteristics of volcanic lavas.

\subsection{Comparative analysis of nutrient contents in volcanic soils}

The content of all N, P, S, C1 and organic matter covered by bryophytes from the suture of the cliff cliff of the fire mountain is obviously higher than that in the crags, while the rest of the mineral elements is lower than that of the volcanic slag. The content of mineral elements such as $\mathrm{K}, \mathrm{Ca}, \mathrm{Mg}$, $\mathrm{Fe}, \mathrm{Mn}$ and $\mathrm{Zn}$ is higher than that in the soil, and the organic matter accumulates continuously in the soil accumulated through the long-term weathering of rock and the settlement of the dust matter, so that the nutrient elements such as $\mathrm{N}, \mathrm{S}$ and $\mathrm{P}$ are accumulated continuously.Soil samples collected below the forest. Among them, the contents of N, S, organic matter, Ca, Fe and Mn in forest soil were significantly higher than those in mixed soil.The soil is close to the soil. It shows that the soil development degree is deeper and the organic matter and other nutrients are accumulated more. Although the rock crevice and the low beauty of the stone pond have accumulated some weathering products and aeolian soil, the content of most soil nutrient elements is lower than that of the undergrowth soil in the same age. However, these soils not only improved the Shitang Lin niche, and provides favorable conditions for access to other higher plants.

\section{Comparison and Analysis of Soil Nutrient Content in Different Soil}

The average value of each nutrient content in the soil of the fire mountain and the old black mountain is taken as the nutrient content of the new period volcano, the average value of the nutrient content of the soil under the West Jiao de mountain and the West Jiao de mountain forest, as the nutrient content of the West Jiao de Bu mountain, and then compared with the other volcanic soils.

With the gradual increase of age, soil development is deepened and organic matter accumulates continuously. $\mathrm{N}$ mainly exists in soil in organic form. S mainly exists in organic matter. Therefore, the accumulation of organic matter in soil increases the content of $\mathrm{N}$ and $\mathrm{S}$. The content of $\mathrm{N}, \mathrm{S}, \mathrm{P}$ and organic matter in the soil of the South Ge La ball volcano is lower than the other old volcanoes, which may be related to the depth of the development of the South green ball mountain and the serious tourism trampling. The content of total $\mathrm{P}$ in all plots is high, and the difference is not the same. Its content has a slight decreasing trend with the change of age. The contents of all $\mathrm{K}, \mathrm{Ca}, \mathrm{Mg}, \mathrm{Fe}, \mathrm{Zn}$ and $\mathrm{B}$ were the highest in the new volcanic soil, and they had a decreasing trend with the increase of the age. The content in nangela ball mountain soil in $\mathrm{Mn}$ is highest, the new period volcano, Molabu mountain was the lowest. The content of a in the soil of the southern part of the globe is the lowest, followed by the new volcanoes and the highest in the west of the west part of the mountain. P, K, Ca, $\mathrm{Mg}, \mathrm{Fe}, \mathrm{Mn}, \mathrm{Zn}, \mathrm{B}, \mathrm{CI}$ and other elements are mainly affected by parent material, weathering degree and leaching intensity. The content of these mineral elements in the new volcano is higher than that in the old volcano, indicating that these elements are greatly influenced by the soil parent material, and the content of these elements may gradually decrease with the influence of the degree of weathering, the degree of soil development and the leaching effect. 


\section{Conclusion}

(1) the coverage of bryophytes in the mixed forest and boulder habitat of the new volcanic Larix is $30 \% \sim 40 \%$, even above $80 \%$, which has a significant effect on the formation of native bare soil and the accumulation of mineral nutrition. (2) the contents of total N, S and organic matter in the old volcanic soils are higher than those in the new volcanoes, and accumulate in the soil with the increase of volcanic age. The content of all P, K, Ca, Mg, Fe, Zn, B and Mn in the new volcanic soil is higher than that of the old volcano. (3) the content of all $\mathrm{N}$ and $\mathrm{S}$ was significantly positively correlated with the content of organic matter, the content of all $\mathrm{K}$ and all $\mathrm{Mg}$ and Fe content was very significant positive correlation, and the total Mg content and total Fe content also showed significant positive correlation. (4) bryophyte is not only conducive to the formation and accumulation of soil, but also to the accumulation of N, P, S, organic matter and soil nutrients. There are CPolytrichum plants in the Haishan mountain soil and the old black hill volcanic gravel (fine slag) sampling sites. (5) sand moss and pendulous moss play an important role in the formation and accumulation of soil and volcanic rock in the old black hill and the soil and water conservation. (6) the life forms of bryophytes in the study area are mainly cushion, cluster and interweave. The dominant species of bryophytes and their associated species in the new period volcano and the old volcano are mainly clustered and interwoven.

\section{Acknowledgements}

The science and technology project of Heilongjiang Provincial Education Department, No. 12531437, the name of the project (Wudalianchi World Geopark bryophyte systematics Research).

\section{References}

[1] Kitagawa M. Neo-Lineamenta Florae Manshuricae [M] Germany: Staues \& Cvamer Gmbh, 1979.

[2] Zhou Zhiqiang, Xu Lijiao, Zhang Yuhong et al. Analysis of [J]. biodiversity ecological value of Longjiang black Wudalianchi, 2011,19 (1): 63 - 70.

[3] Liu Yanhua. Investigation of wild plant resources in Wudalianchi volcano conservation area [D]. Yanji: Master degree thesis of Yanbian University, 2006.

[4] Zhang Chongbang, Zhang Zhongheng, Zhang Chongyao. The vegetation types and Protection Countermeasures of the Wudalianchi volcano group [J]. Journal of Qigihar Normal College: Natural Science Edition, 1997,17 (3): 58-61.

[5] Yu Shuang, Qu Xiuchun, Zhang Yongle, et al. Study on Flora of Heilongjiang province. Journal of Northwest Forestry College, 2008,23 (2): 42 - 48., [J]. 